\title{
El arte contemporáneo como reflexión social: una aproximación a la obra de Regina José Galindo
}

\author{
Contemporary Art as a Social Reflection: \\ an Approach to the Artwork of Regina José Galindo
}

Marcela Otárola Guevara

\section{(c) $(1)(9)$}

Esta obra está bajo una licencia Creative Commons Reconocimiento-No comercial-Sin Obra Derivada 


\title{
El arte contemporáneo como reflexión social: una aproximación a la obra de Regina José Galindo \\ Contemporary Art as a Social Reflection: an Approach to the Artwork of Regina José Galindo ${ }^{1}$ \\ Marcela Otárola Guevara ${ }^{2}$ \\ Universidad Nacional de Costa Rica \\ Costa Rica
}

Recibido: 28 de junio de 2019 Aprobado: 18 de febrero del 2020

\begin{abstract}
Resumen
El arte contemporáneo emerge en el siglo XX y se destaca por el cambio de un paradigma, derivado de una nueva forma de vinculación entre el artista y la sociedad. Para apreciar tal relación, se procede a analizar cualitativamente algunas obras de una exponente de este movimiento, Regina José Galindo, a partir de un cuestionamiento y posterior interpretación sobre las razones que han originado sus producciones. Tal ejercicio requirió estudiar premisas teóricas procedentes de la sociología, la filosofía y la historia del arte. Las piezas seleccionadas refieren a temas asociados a la memoria, la mujer y las relaciones de poder. Además, muestran la empatía y la apropiación espacial como mecanismos de articulación social y revelan los alcances de sus propuestas: exponer a las personas oprimidas, interpelar al espectador y conceder valor al contexto.
\end{abstract}

Palabras clave: arte contemporáneo; sociología del arte; Regina José Galindo; memoria colectiva

1 La autora agradece a quienes participaron en la lectura preliminar, en la evaluación y en la edición de este artículo, por los comentarios y recomendaciones realizadas que permitieron mejorarlo.

2 Profesora e investigadora de la Escuela de Historia, Facultad de Ciencias Sociales de la Universidad Nacional de Costa Rica (UNA). Doctoranda del doctorado de Estudios de la Sociedad y la Cultura de la UCR. ORCID 0000-0003-0627-4275. Correo electrónico: zaida.otarola.guevara@una.ac.cr 


\begin{abstract}
Contemporary art emerges in the 20th century and stands out for the change of a paradigm, derived from a new way of linking the artist and society. In order to appreciate such relationship, it is proceeded to qualitatively analyze some works of an exponent of this movement, Regina José Galindo, from a questioning and later interpretation on the reasons that have originated her productions, exercise that required studying theoretical premises coming from sociology, philosophy and history of art. The selected pieces refer to themes associated with memory, women and power relations; they show empathy and spatial appropriation as mechanisms of social articulation and reveal the scope of her proposals: to expose oppressed people, to question the viewer and to give value to the context.
\end{abstract}

Keywords: contemporary art; sociology of art; Regina José Galindo; collective memory 
El arte contemporáneo como reflexión social:

Dossier

una aproximación a la obra de Regina José Galindo

\section{Introducción}

El presente artículo aborda la relación entre el arte contemporáneo y la sociedad a través del trabajo de la artista Regina José Galindo, quien, a lo largo de dos décadas de quehacer creativo, ha tratado el tema de la violencia y otros tópicos que han gravitado alrededor de este. En el primer apartado de este escrito, se exponen preceptos teóricos que permiten interpretar los discursos que subyacen en los performances de esta autora. En la segunda sección se muestran obras que han sido agrupadas según sus temas, relacionados con la memoria, la mujer y las formas de relacionar el arte con la sociedad. Posteriormente, en una tercera parte, se dilucidará el trasfondo de una vinculación artística-social que se centran en tres aspectos: la exposición de pueblos oprimidos, el efecto de la dislocación en el espectador y la impronta del contexto. Finalmente, se reflexiona sobre las razones que mueven a Regina José Galindo a realizar sus proyectos y los argumentos que justifican por qué se considera una artista contemporánea.

Como complemento a lo descrito y con en el fin de hacer un acercamiento preliminar al trabajo de Galindo, es necesario mencionar que ella nace en Guatemala en 1974 e inicia su trayectoria artística como poeta en la década de 1990. En las postrimerías de dicha década y motivada por amigas diseñadoras (Galindo, 2017a, 1:04), incursiona de modo autodidacta en las artes visuales a través del performance. Por ello, estudia a artistas conceptuales como Aníbal López, Ana Mendieta y Chris Burden, quienes serán sus referentes y cuya influencia se aprecia en sus proyectos. Desde 1999, ha generado una vasta producción que contabiliza casi 90 exposiciones individuales alrededor del mundo y casi el doble de manera colectiva, según se observa en el currículum de su sitio web (Galindo, s.f.b) ha participado en más de treinta bienales de arte y ha cosechado alrededor de 10 galardones entre los que destaca el León de Oro al Mejor Artista Joven obtenido en la $51^{\circ}$ Bienal de Venecia (2005). Si bien se desplaza a otras latitudes a dictar charlas y realizar sus performances, radica en su país natal donde continúa su práctica artística y social.

\section{Un abordaje teórico para la interpretación}

Para analizar la obra de Regina José Galindo es necesario precisar qué es arte contemporáneo con el fin de comprender cómo su trabajo se vincula con este movimiento. Se tomarán en consideración los aportes de la socióloga Nathalie Heinich (2017) y del filósofo Giorgio Agamben (2011), principalmente, aunque a lo largo del texto también se hará referencia, de forma puntual, a contribuciones de otros teóricos que permiten ampliar la interpretación de sus piezas.

ESCENA. Revista de las artes, 2021, Vol. 80, Núm. 2 (enero-junio), pp. 171-197 
En primera instancia, Heinich plantea que el arte contemporáneo no es una categoría cronológica (2017, p. 27) y cita a la historiadora Julie Verlaine para presentar uno de sus rasgos más importantes: la ruptura con el arte moderno. Así, establece una nueva forma de vincular el arte con la realidad; acto que demanda una mirada liberada (Heinich, 2017, p. 33). Este tipo de mirada no solo se aparta de convenciones figurativas y de corrientes artísticas anteriores, sino también de requerimientos constitutivos. Por ello, ya no se aprecia la interioridad del artista, pues sus obras, elaboradas con materiales no tradicionales, son producciones en las que priman la experiencia y la creación (Heinich, 2017, p. 35).

Para esta socióloga, el arte contemporáneo es, además, un nuevo paradigma, y para explicar esta afirmación, refiere al epistemólogo Thomas Kuhn, quien lo definió como un conjunto de concepciones, legitimadas y estructuradas en un momento dado, que están relacionadas con un ámbito de la actividad humana (citado en Heinich, 2017, p. 47). Según Kuhn, para construir un nuevo paradigma se necesita, entre otras cosas, de una controversia que genere desacuerdos de manera tal que, a partir de las discrepancias, se propongan nuevas propuestas y formas de resolver inquietudes (Kunh citado en Heinich, 2017, p. 49). A partir de un desacuerdo en la forma de crear e interpretar una obra, acorde a lo propuesto por el arte moderno, surge el arte contemporáneo como paradigma (Heinich, 2017, p. 57). En este se aprecia que la obra ya no se expresa a través de una técnica convencional artística, como la pintura o la escultura, y que tanto su definición como su representación han sido alteradas. Estos cambios modificaron el quehacer de críticos, quienes debieron repensar la noción de arte y de los marchantes, ahora llamados galeristas, en alusión a los nuevos espacios requeridos para la apropiada presentación de las obras contemporáneas, las galerías (Heinich, 2017, p. 58).

La ruptura que condujo al cambio de un paradigma artístico tuvo como principal actor al artista, particularmente, en lo atinente a la relación con sus piezas. En el arte moderno primó la elaboración de pinturas y esculturas en las que se manifestaba la interioridad del individuo y la identificación entre el autor y su obra. Estas situaciones que no ocurren en el contemporáneo porque el autor, en aras de desprenderse de todo aquello que otorgue autenticidad a sus producciones, toma varios tipos de distancias para desmarcarse de ellas (Heinich, 2017, p. 71). El distanciamiento al que alude Heinich (2017) es una manera de expresar su oposición a "las normas estéticas, axiológicas y jurídicas que rigen el arte moderno" (p. 76) y refiere también a un ejercicio que hace el artífice para despersonalizar la obra. No obstante, es importante mencionar que la toma de distancia, esta vez con respecto a la 
El arte contemporáneo como reflexión social:

Dossier

una aproximación a la obra de Regina José Galindo

observación de su propia época, también es lo que define su contemporaneidad. Giorgio Agamben (2011) lo plantea así al afirmar que quien se abstrae de su tiempo, se "adhiere" a él mediante un desfase o anacronismo (p. 18). Este alejamiento que, lejos de desubicarlo fuera de su época, le permite tener consciencia de ella como su presente y allí logra percibir una oscuridad que le incumbe e interpela (Agamben, 2011, p. 22).

La advertencia de tal oscuridad constituye la segunda característica del ser contemporáneo, según Agamben (2011). La persona que mira la oscuridad está alerta y mira a su alrededor de forma crítica para identificar luces de su época que, dirigidas hacia ella, se mantienen lejanas (Agamben, 2011, p. 23). Se trata de la circunstancia que revela una suspensión entre lo vivido y lo no vivido, entre un "ya" y un "no todavía" que refiere al presente (Agamben, 2011, p. 24). El presente se muestra, entonces, en relación con el pasado. Agamben se centra en él porque considera que en esta temporalidad yace lo arcaico, lo cercano al origen, y que tiene injerencia en lo actual, pues es en el ahora donde se acarrean las secuelas de un devenir histórico (Agamben, 2011, p. 26). Desde de esta perspectiva, el filósofo considera necesario practicar una arqueología para comprender el presente. Es decir, se requiere hurgar en el pasado para identificar lo no vivido que se ha mantenido oculto, sea por un trauma o por excesiva cercanía; tarea que recae en el sujeto contemporáneo (Agamben, 2011, p. 27).

El trabajo de Regina José Galindo es un ejemplo de este quehacer. Nació y creció en un país aquejado por conflictos bélicos internos. Por ello, en sus obras se aprecia el tema de la memoria como un acto de resistencia ante los silencios y olvidos, que han sido inducidos por quienes, durante décadas, han tratado de ocultar las infamias hechas a las víctimas de esos enfrentamientos, en su mayoría mujeres. Observar la opacidad de su época le ha permitido identificar las heridas, provocadas por un gobierno autoritario, las cuales, aun hoy, se mantienen abiertas y aquejan a poblaciones que han sido vulnerabilizadas. En este sentido, se advierte el carácter contemporáneo de su ejercicio artístico al recurrir al anacronismo para interpelar al pasado y, así, intervenir en su proyección. Ella observa y valora los eventos a partir de la realidad presente y, desde allí, le otorga una significación, con la cual pretende elucidar lo omitido u ocultado en crónicas hegemónicas.

En congruencia con lo que expuso Heinich (2017), se afirma que lo contemporáneo se distingue, en este caso, en el uso que hace la artista de su propio cuerpo como sustrato no convencional para la producción de algunas de sus obras. Su cuerpo es empleado con el fin de relatar e ilustrar la vejación hecha a la mujer y evitar que la versión universal, la legitimada 
e instituida desde los masculino, adultere el testimonio. Asimismo, sus performances, muchos de ellos realizados en espacios públicos, apelan a la vivencia para sustraer al espectador de su contemplación y provocarlo intempestivamente, por eso, recurre a estrategias para involucrarlo de forma activa (al tomar partido del performance); o bien, exacerba sus sentidos de modo tal que cada obra se torna en una experiencia perecedera.

\section{Algunos temas presentes en la obra de Regina José Galindo}

Con el objetivo de detallar la forma en que Galindo se vincula con el presente y escudriña en él para denunciar, de seguido, se presenta la interpretación de algunas de sus obras donde instaura una memoria histórica alterna. Adicionalmente, desde una perspectiva feminista y mediante lo abyecto, reposiciona a la mujer ante la barbarie que ha socavado su integridad humana.

\section{La memoria}

Galindo logra impactar emocionalmente a los espectadores a través de sus performances y happenings, pues se emplea a sí misma como un texto que evidencia la violencia presente en la sociedad. Al observar su desempeño surge la interrogante, ¿cuál es la razón que la motiva a hacer sus obras? Para obtener una respuesta se requiere repasar un episodio de la historia de su país natal. Varias de sus producciones están asociadas al tema de la memoria, acto que se interpreta como un interés en denunciar crímenes cometidos durante la guerra civil de Guatemala, ocurrida entre los años 1960 y 1996. Este conflicto ha desencadenado hechos violentos que no han cesado a pesar de los esfuerzos por lograr la paz. La desigualdad social y la corrupción causaron el enfrentamiento entre grupos armados insurgentes y contrainsurgentes.

Según el estudio realizado por la economista Katherine Aguirre Tobón (2014), el conflicto dejó un saldo de 200000 personas asesinadas o desaparecidas y tuvo por crimen común las ejecuciones extrajudiciales y los actos de tortura. En esta investigación se reveló, además, que el ejército fue el responsable del 85\% del total de las violaciones; el 90\% de las víctimas de la conflagración vivían en áreas rurales, y el 83,3\% eran mayas. Sin embargo, uno de los hallazgos más significativos fue la violencia contra la mujer ejercida por agentes del Estado, mediante la violación sexual generalizada y sistemática, como estrategia para implantar el terror en los rebeldes. Las secuelas de estos actos perviven y se mantienen impunes, según consta en estudios hechos por la Consejería en Proyectos y la Fundación Sobrevivientes, organizaciones citadas por Aguirre Tobón en su pesquisa (p. 202).

ESCENA. Revista de las artes, 2021, Vol. 80, Núm. 2 (enero-junio), pp.171-197 
EL trabajo de Regina José Galindo ha tenido por motivación la denuncia de abusos cometidos por autoridades gubernamentales; razón por la que las vejaciones a la mujer son un tema constante. Así lo expresó en el programa Alemania con acento donde fue entrevistada (Galindo, 2014a, 6:27). En el registro de sus performances, ubicado en su página web, se encuentran las imágenes de sus obras acompañadas de textos. Muchos de ellos son extractos de testimonios contados por víctimas o descripciones de las arbitrariedades padecidas en la época de guerra. Incluso sus títulos aluden a los actos de barbarie que denuncian: ¿Quién puede borrar las huellas? (2003), Mientras ellos siguen libres (2007), La verdad (2013) y Testimonios (2014) son algunos ejemplos. Ella también aborda el resentimiento por la negación de los delitos de guerra perpetrados por militares, a pesar de que fueron catalogados de lesa humanidad y genocidio en los tribunales de justicia de su país (Galindo, 2014a, 35:36).

Por esta razón, la artista elabora una memoria para luchar contra la arbitrariedad. Para ello, realiza un montaje, "una organización impura" (Didi-Huberman, 2006, p. 59) en la que recoge y articula narraciones que son interpretadas desde su propia experiencia y expuestos a través de su cuerpo o mediante sus acciones. Afirma Didi-Huberman que la memoria reconstruye el pasado, le despoja de su exactitud y lo humaniza (2006, p. 60). Galindo recurre a la corporalidad y a la poesía para para expresar las múltiples voces que demandan ser escuchadas porque son parte de un relato excluido de los discursos de los grupos de poder. Así, consigue recoger todas aquellas experiencias, traumáticas y dolorosas, para elaborar una memoria de la represión. En ella convergen sentimientos que conforman una emocionalidad común y que conducen a un no olvidar.

Con los performances, la artista retrotrae el conflicto armado, visibiliza los traumas de las víctimas y estiliza la experiencia para crear imágenes que luego incorpora en la narrativa histórica de su país. En Mientras ellos siguen libres (2007) usa como sustrato para su obra el siguiente testimonio: "fui violada consecutivamente, aproximadamente unas 15 veces, tanto por los soldados como por los hombres que vestían de civil. Tenía siete meses de embarazo, a los pocos días aborté" (Guatemala: Memoria del silencio, citado en Galindo, 2007, párr. 2). Con base en él elaboró una representación que describió de la siguiente forma: "con ocho meses de embarazo, permanezco atada a una cama-catre, con cordones umbilicales reales, de la misma forma que las mujeres indígenas, embarazadas, eran amarradas para ser posteriormente violadas durante el conflicto armado en Guatemala" (Galindo, 2007, párr. 3). Este ejemplo denota el uso del testimonio para desarrollar una evocación que le permite 
a la memoria trascender su concepción como depositario de acontecimientos pasados. De esta forma, le otorga una cualidad activa: se constituye en una imagen que se instala en el presente para cuestionar el devenir y, a la vez, interpelar al futuro.

Por su parte, en La verdad (2013) complementa la imagen de los performances con el siguiente texto: "durante una hora leo testimonios de sobrevivientes del conflicto armado en Guatemala, mientras un dentista intenta silenciarme, anestesiándome la boca, una y otra vez" (Galindo, 2013, párr. 4). Mientras que Testimonios (2014) se acompaña del siguiente escrito: "estos testimonios esculpidos en hierro fueron escuchados durante el juicio. Para que la voz y palabras de las mujeres que contaron su historia no se olviden" (Galindo, 2014b, párr. 2). En este conjunto de textos e imágenes se muestra la re-visitación a un pasado que no se manifiesta como un cúmulo monolítico de hechos, sino como una sustancia sujeta a miradas procedentes de posiciones diversas, en espacio y tiempo, susceptible a varias aprehensiones. Galindo usa las palabras y las incorpora en su obra para demostrar la brutalidad encubierta en los relatos de la guerra. Además, los trae al presente para demandar el cumplimiento de la justicia y establecer un precedente que evite la reproducción de la barbarie. Motivo por el cual se infiere que, en esencia, ella lucha por un cambio político y cultural (ver imágenes 1 y 2).

Imagen 1. La verdad

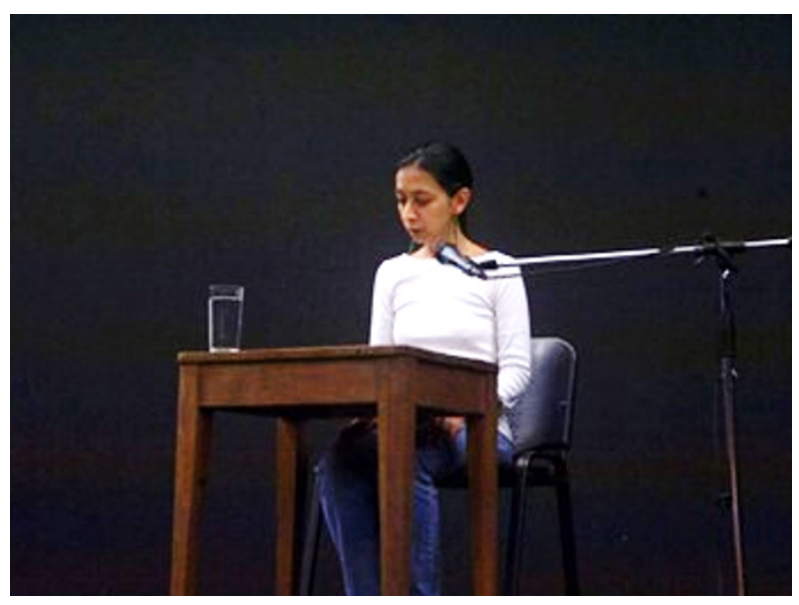

Fuente: Pérez y Linares (2013).
Imagen 2. La verdad

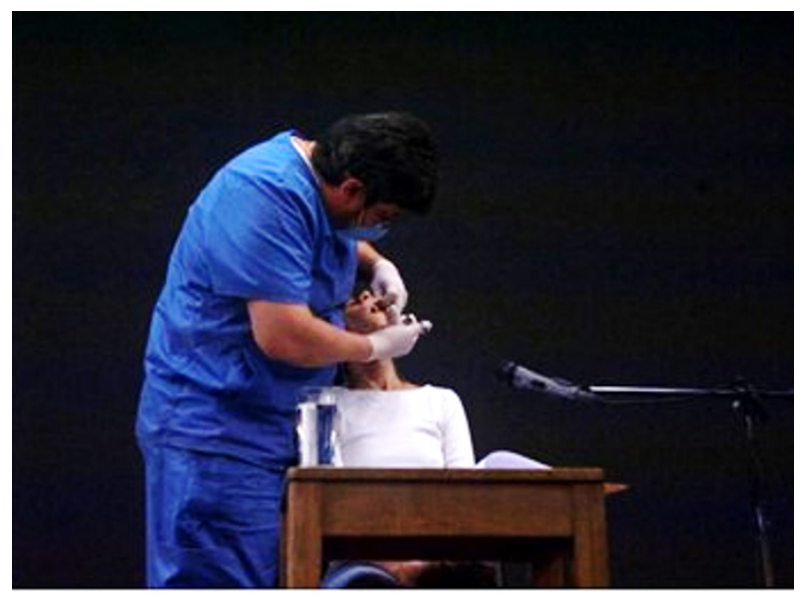

Fuente: Pérez y Linares (2013). 
En la praxis de la artista se aprecia la contemporaneidad de su obra. En ¿Quién puede borrar las huellas? (2003) realiza una caminata entre la Corte de la Constitucionalidad y el Palacio Nacional de Guatemala para censurar la candidatura a la presidencia del exmilitar genocida Efraín Ríos Montt. En el trayecto, planta huellas de sangre humana para mostrar la impronta de muerte y terror dejada por el entonces aspirante presidencial en su país. Así, evidencia la oscuridad que suponen las prebendas políticas que intentan perpetuar a grupos hegemónicos. Su trabajo combate la amnesia que procuran instaurar tales cámaras para omitir un pasado signado por el abuso. Por ello, además de reiterar los temas en sus obras, procede a exhibirlas en importantes espacios simbólicos.

En Corona (2006) rememoró los diez años de la firma de los Acuerdos de paz en Guatemala y elaboró un tributo en gran escala: un aro floral de 4,50 metros de diámetro, en alusión a las personas asesinadas ese año. De este modo, denunció que la brutalidad pervive. El anillo fue instalado en la Plaza Central de Guatemala, frente al Palacio Nacional de la Cultura, sede del Gobierno central de esa nación. Este constituyó un gesto que expuso ante las autoridades políticas la perenne práctica funeraria que realiza el pueblo en el proceso de recuperación de los cuerpos de sus desaparecidos. La elaboración de Corona es un recurso sígnico que plantea un desafío a los grupos de poder: la presencia de este objeto simbólico funerario en el centro neurálgico, donde se proyecta una soberanía hegemónica, es una transgresión que perturba un discurso oficial conciliatorio. Se trata de una alocución derivada de una supuesta concordia, porque descubre la poca efectividad en la erradicación de la violencia, tras la firma de los Acuerdos de paz.

Otra muestra de este "no olvido" es Bandera negra (2000), producción que consiste en la exposición de una bandera monocromática de Guatemala colocada en distintos edificios, la mayoría en ubicados en zonas céntricas, para representar el luto y protestar contra la opresión. Esta obra la ha realizado varias veces en diferentes locaciones, pero fue en Xela, Quetzaltenango, donde este símbolo causó mayor revuelo al ser retirado por el gobernador de la ciudad. Con este acto, el jerarca validó la denuncia de Galindo referente a la existencia de una censura y a la negación de toda oportunidad de transformación social, acusación expresada en las siguientes declaraciones:

la verdad es que es una molestia muy grande porque yo estoy en contra de cualquier medida represiva y de censura, todo individuo tiene derecho de manifestar sus emociones y sentimientos de repudio hacia una situación y este tipo de censuras solo enciende la molestia, ya que es una forma pacífica de demostrar lo que estamos 
sintiendo. Estas cuestiones dictatoriales de decir no se pueden, pues no llevan a caminos de diálogo, lo que el país necesita básicamente es un cambio y diálogo, pero debido a estas medidas represivas, no hay salida (Galindo citada en De León, 2017, párr.11).

Con la creación de memoria, la artista no solo muestra omisión y avasallamiento, sino que evoca el sufrimiento y el ultraje. Conmemora el horror que suscita la violencia y ese mismo sentimiento es lo que proyecta en su obra. Este desempeño es congruente con su enfoque feminista; posición ideológica a partir de la cual transforma espacios marginalizados en espacios de subversión política, por medio de una producción artística que usa el cuerpo femenino como su materia, herramienta y medio (Antivilo, 2013, p. 123).

\section{El feminismo}

El arte feminista tiene varias características. Sin embargo, para este artículo interesan dos que se encuentran presentes en la obra de Galindo: el desmantelamiento de discursos universales y la creación de nuevas categorías estéticas a partir de la experiencia femenina (Antivilo, 2013).

\section{Supresión de lo universal-masculino}

La pugna por incorporar los testimonios de las víctimas de guerra en la narrativa histórica de Guatemala ha sido una forma de destruir el relato único y hegemónico sobre el conflicto armado. Dicho proceso integra y visibiliza el papel desempeñado por las mujeres. En Isle'l in (2015), frase en lengua ixil que significa "estoy viva", Galindo rinde tributo a las mujeres ixiles, pues en ellas reconoce la perseverancia por comunicar su versión sobre el genocidio:

La fuerza y valentía con la que las mujeres Ixiles se han enfrentado a una Guatemala que niega su historia y que niega el genocidio, es admirable. Ellas, con su verdad, nos han mostrado un camino de luz. Nos han dado una verdadera lección de vida (Galindo, 2015, párr. 2).

Empero, además del relato histórico, también pretende deconstruir la narración de un evento que, por lo general, se ha contado desde una perspectiva masculina. Por este motivo, suprime las declaraciones de los hombres como referencia única para su elaboración e incorpora y privilegia los testimonios de mujeres sobrevivientes, con el objetivo de que denuncien los crímenes que padecieron para así, dimensionarlos desde su experiencia. 
El arte contemporáneo como reflexión social:

Dossier

una aproximación a la obra de Regina José Galindo

Derrocar los testimonios universales también ha implicado para la artista cuestionar convencionalismos sociales que determinan y valoran a la mujer, los cuales se han instaurado de forma absoluta para complacer a los hombres. En el año 2004, Galindo hace dos piezas: Himenoplastia, imágenes que muestran una cirugía de reconstrucción de himen a la que se sometió para volver a ser virgen y Boda Galindo-Herrera, una escena fotográfica en un estudio donde, vestida de novia, posa sola para un retrato de bodas. En ambos casos se observan roles específicos otorgados a la mujer dentro de una sociedad patriarcal: la virgen y la esposa. No obstante, Galindo subvierte esas funciones para denunciar, por una parte, prácticas validadas y exacerbadas para la satisfacción masculina. Por otra, la situación de mujeres que conviven con la ausencia de sus compañeros sentimentales como consecuencia de la guerra.

En Himenoplastia, la virginidad no existe, la reconstrucción del himen es una tachadura del pasado sexual femenino. A partir de esta, se reafirma el posicionamiento de la figura de la mujer como sujeto de fantasía y objeto de deseo. El imaginario al que apela la obra es el mismo que nutre el comercio de trata de personas con fines de explotación sexual que, en Centroamérica, afecta en una gran proporción de la niñez y la adolescencia. Con esa obra, Galindo pone en escena los múltiples apetitos que conducen, de nuevo, al sometimiento y a la vejación de la mujer. El más explícito está asociado con la imagen que remite a la virginidad de la imberbe y pervive para satisfacer la avidez sexual masculina. También se puede leer la necesidad que emerge por la carestía material, la cual motiva el trasiego para la explotación sexual y laboral de niñas y adolescentes pobres guatemaltecas (Fondo de las Naciones Unidas para la Infancia [UNICEF] y Comisión Internacional contra la impunidad en Guatemala [CICIG], 2016). Además, se evidencia la ambición de una industria médica que, en aras de lucrar con la apariencia de la mujer, invade una de sus partes más íntimas, la vagina.

En Boda Galindo-Herrera la artista muestra la ficción del matrimonio que viven mujeres como las ixiles, cuyos familiares fueron arrebatados por la represión militar y que, actualmente, permanecen desaparecidos. Muchos de estos individuos fueron sus maridos y tras su ausencia, en solitario, las esposas asumen la representación de una unión que está incompleta. Si bien la imagen de la boda remite a un sacramento religioso para gente de alcurnia, la misma sacralidad se percibe en eventos conmemorativos del pueblo Ixil. Esta se evidencia, principalmente, en la Marcha del Día de la Dignidad y la Resistencia del Pueblo (Chiquin, 2013), celebrada en la localidad de Nebaj: las mujeres desfilan, bien ataviadas, con 
flores en sus manos por las calles principales de la ciudad. Llevan consigo las imágenes o emblemas de sus parejas porque, aunque desaparecidas, su presencia no ha sido escamoteada. Entonces, ¿es el matrimonio una ilusión para estas mujeres? Desde la materialidad del cuerpo lo es, porque no está la contraparte de la unión; pero, desde lo simbólico, el vínculo permanece tácito, pues el cónyuge existe mientras no se borre de la memoria de la desposada. Complementariamente a las apreciaciones aquí comentadas, se infiere que las mujeres representadas por Galindo no son vírgenes ni son esposas. De esta forma, trastoca el discurso conservador que las ha perfilado desde una perspectiva masculina; valoración que se ha implantado como una mirada universal para dominarlas.

\section{Lo abyecto como categoría estética}

En el trabajo de Galindo se hacen presentes nuevos conceptos desde una nueva categoría estética: lo abyecto, con el cual evoca el terror y el dolor a través del rechazo, y la repulsión. Julia Kristeva, en Poderes de la perversión (1988), define lo abyecto desde una perspectiva psicoanalítica e instituye la expulsión como una condición necesaria para la construcción de la identidad humana. De modo tal que el individuo se reconoce preliminarmente por su separación del cuerpo materno y en los humores segregados que fueron partes co-sustanciales de su organismo. En lo expelido, entonces, se encuentra una parte esencial del ser. Ello genera sensaciones paradójicas de repugnancia y atracción, por cuanto el ser se distingue en aquello que le genera una perturbación en su identidad y que le arrebata, a la vez, lo abyecto que resulta: "algo rechazado del que uno no se separa, del que uno no se protege de la misma manera que de un objeto. Extrañeza imaginaria y amenaza real, nos llama y termina por sumergirnos" (Kristeva, 1988, p. 11). Lo abyecto implica una alteración de identidades establecidas y supone la transgresión a un orden. Acto que trasciende a la constitución del individuo y se extiende a otras manifestaciones humanas por cuanto se trata de una "experiencia de cruzar límites y manejar prohibiciones" (Ciénega, s.f., p. 3).

En la producción de Regina José Galindo, esta categoría estética se emplea para dislocar significaciones a partir de la contradicción atracción-repulsión. Para eso, recurre al uso de fluidos humanos entre los cuales destacan la sangre y la orina. En Ablución (2007) un expandillero lavó con agua un litro de sangre vertido en su cuerpo desnudo. Gesto con el que la artista resignifica un rito religioso de purificación y lo plantea como una forma de expiación de la culpa por haber lesionado físicamente a una persona. El hombre reconoció su infamia y procedió a limpiar la evidencia de su yerro con agua (ha eliminado de su cuerpo 
El arte contemporáneo como reflexión social:

Imagen 3. Ablución

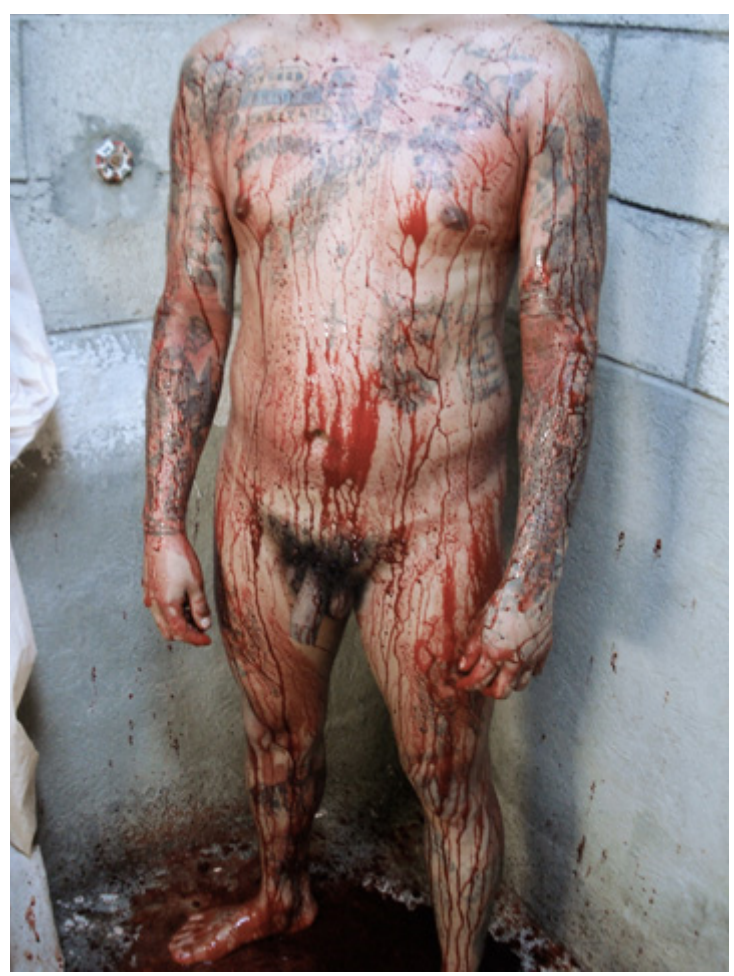

Fuente: Pérez (2007).

\section{Imagen 4. Ablución}

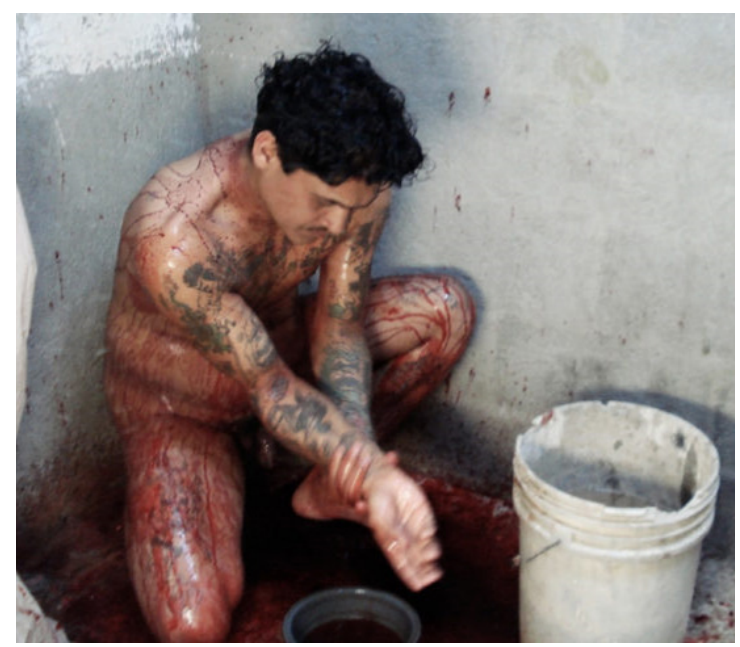

Fuente: Pérez (2007). la sangre del lastimado), lo cual se lee como un acto de contrición que reafirma su condición de exproscripto (ver imagen 3 y 4).

Contradictoriamente, en El peso de la sangre (2004), performance realizado en la Plaza Central de Guatemala, Galindo se colocó bajo una estructura con una bolsa de sangre de la cual goteaba el líquido. La sangre cayó y manchó su cuerpo en alusión a las muertes del genocidio que están impunes. Las mismas que yacen en la corporalidad de sus perpetradores, sujetos que no reconocen su culpa y tampoco han sido señalados por las autoridades judiciales. En ambas expresiones artísticas se hace referencia a los cuerpos ausentes de las víctimas, los cuales se materializan en la sangre vertida en los participantes del performance. La aversión que genera este líquido se traslada a la repulsión del crimen y revela, además, la amenaza que representa la agresividad que se ha imbricado en la sociedad guatemalteca tras la guerra civil. Agresividad que no logra ser aplacada por la existencia de un débil sistema gubernamental. Por lo tanto, la sangre derramada también es la sangre de un pueblo que aún no cicatriza sus heridas, dada la fragilidad de su sistema político; líquido que revela una situación que, por siniestra, los grupos de poder no desean que sea expuesta.

En un ámbito más personal, Galindo emplea la orina para representar a la mujer que se aferra a su existencia. En Isla (2006) se coloca sobre unos arrecifes superficiales a la orilla 
del mar, donde yacen sus orines y, sobre ellos, se ubica desnuda en posición fetal. En esta obra se observa la soledad y la parálisis de quien, consciente de su vulnerabilidad y para subsanar su frágil condición, orina para repeler el peligro. Una acción fisiológica que se activa espontáneamente en los animales para preservar la vida. Mientras que en Piedra (2013), con su cuerpo desnudo, cubierto de carbón, se colocó de cuclillas y reposó el tórax sobre sus muslos en un espacio público para emular una roca que fue orinada por voluntarios. Con este gesto, a través de su cuerpo, la artista simboliza la dureza de la mujer que sobrevive a los ultrajes de la opresión.

En los ejemplos citados se observa el uso de lo abyecto para estilizar los efectos de la barbarie y, de esta forma, quebrantar la identidad construida de sus víctimas y verdugos. Sin embargo, ¿no es la barbarie una transgresión en sí? Lo es, por esta razón, en lo abyecto se encuentra la categoría más pertinente para expresar el horror de un episodio histórico marcado por la sistemática violación de la integridad humana.

\section{Estrategias de vinculación entre el arte y la sociedad}

¿Cómo articula Galindo su trabajo a la sociedad? Lo hace de dos formas: mediante la empatía con las víctimas y a través de la ocupación de espacios públicos (sitios de convergencia y enunciación social) para la expresión de sus proclamas. En este apartado corresponde analizar con detalle estos aspectos.

\section{El cuerpo político y el cuerpo social}

Por su posición feminista, en la obra de Galindo destaca el uso político de su propio cuerpo, como expresión del cuerpo social de las mujeres (Antivilo, 2013). Este se encuentra marcado por los ultrajes sexuales, los cuales tienen un alto índice de impunidad en Guatemala (Galindo, 2017b). Por cuerpo social, se concibe la construcción cultural de una colectividad humana que está determinada por un contexto. Tal acepción procede de las reflexiones de David Le Breton (2002). El autor se ha abocado a estudiar el cuerpo desde la Sociología y lo ha definido como materia devenida de lógicas sociales; elaborada a partir de acciones cotidianas y sujeta a representaciones e imaginarios que configuran un sentido en el individuo: "del cuerpo nacen y se propagan significaciones que constituyen la base de la existencia individual y colectiva" (p. 7). De acuerdo con esta consideración, el cuerpo social que acoge Galindo es el cuerpo de las mujeres de su pueblo. En su poema titulado "Soy un lugar común", esto queda expuesto de modo contundente: 
El arte contemporáneo como reflexión social:

Dossier

una aproximación a la obra de Regina José Galindo

\author{
Soy un lugar común \\ como el eco de las voces \\ el rostro de la luna. \\ Tengo dos tetas \\ -diminutas- \\ la nariz oblonga \\ la estatura del pueblo. \\ Miope \\ de lengua vulgar \\ nalgas caídas, \\ piel naranja. \\ Me sitúo frente al espejo \\ Y me masturbo.
}

Soy mujer

la más común

entre las comunes (Galindo, s.f.).

Otra expresión del cuerpo social se observa en el uso político de su cuerpo para censurar la agresión a la mujer. Tema que ha tratado desde el inicio de su carrera, como se observa en El dolor en un pañuelo (1999) y en (279) golpes (2005). En el primer caso, la artista se sujeta a una cama vertical y sobre su cuerpo desnudo se proyectan noticias de violaciones cometidas en Guatemala. De forma análoga, la segunda obra mencionada consiste en un performance sonoro. Encerrada en un cubículo, la creadora se auto inflige un golpe por cada mujer asesinada en su país, durante el primer semestre del 2005. Se contabilizaron en ese momento 279. El sonido de cada golpe se amplificó en una sala. En este ámbito, la denuncia que realiza la artista no cesa porque las vejaciones en las mujeres continúan y asumen diversas formas de operar. Así, por un lado, en La siesta (2016) delata la violación silenciosa; transgresión que se produce al colocar un medicamento en la bebida de la víctima para sedarla y violarla sin que ella pueda ofrecer resistencia (ver imágenes 5 y 6).

Por otro lado, su cuerpo es empleado para evocar la justicia que han demandado las mujeres indígenas de su país. Por esta razón, en Hermana (2010) se expone a las agresiones físicas ocasionadas por otra mujer y lo describe de la siguiente manera: "mi cuerpo ladino es abofeteado, escupido y castigado por una mujer indígena guatemalteca" (Galindo, 
2010, párr. 1). En el acto, Galindo representa la corporeidad del ladino opresor que ha martirizado al pueblo indígena. Mientras que, al segundo, como compensación, se le otorga el derecho de castigo para así resolver la impunidad que le ha sido negada.

Imagen 5. La Siesta

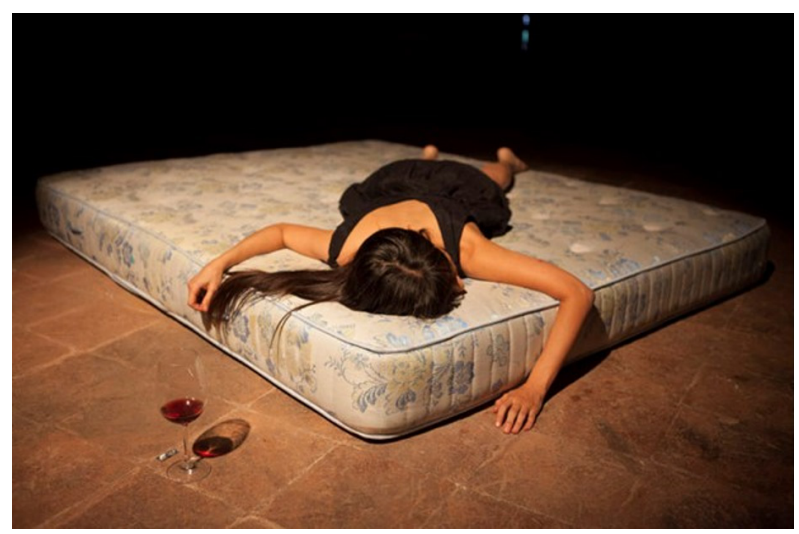

Fuente: Nari (2016).
Imagen 6. La Siesta

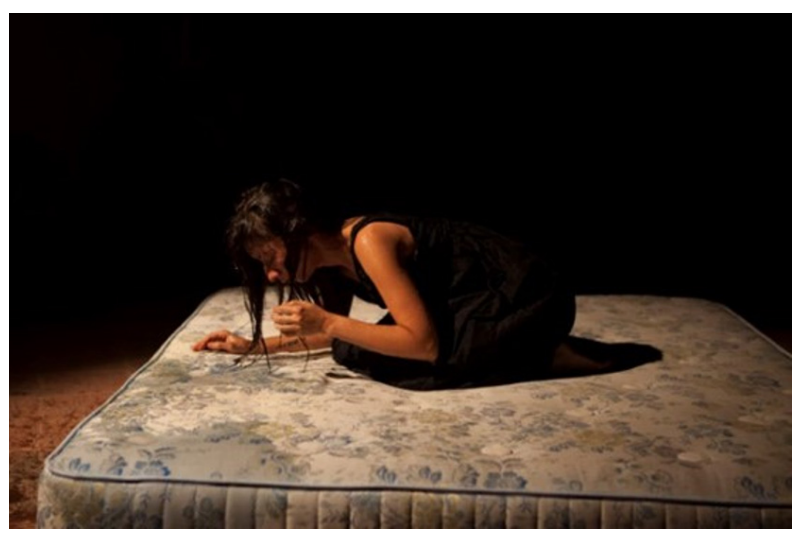

Fuente: Pérez y Linares (2013).

Uno de los casos en el que se revindicó a la comunidad indígena quedó registrado en su performance Ascensión (2016). En este se celebra la condena de dos sujetos que esclavizaron a mujeres q'eqchies durante la guerra civil guatemalteca. La obra se desarrolló en el interior de una iglesia italiana, donde la artista se colocó a diez metros de altura y usó un perraje (prenda típica que semeja un chal) del mismo largo, en alusión al atuendo que emplearon las ofendidas durante el juicio para proteger su identidad, el cual, tras el veredicto, se quitaron para simbolizar la victoria (ver imagen 7).

El cuerpo social, proyectado por la artista a través del propio, expone el efecto del abuso que procede de la violencia. La complejidad de este fenómeno ha implicado una segmentación para poder determinar su alcance. Durante el postconflicto en Guatemala se han identificado siete tipos de violencia (Aguirre, 2014, p. 198). En tres de tres ellos, se menciona como característica, de manera explícita, su rutinización; es decir, su incorporación en la cotidianidad. Esta situación elucida su implicación en la lógica que construye la materialidad social. 
El arte contemporáneo como reflexión social:

Dossier una aproximación a la obra de Regina José Galindo

Imagen 7. Ascensión

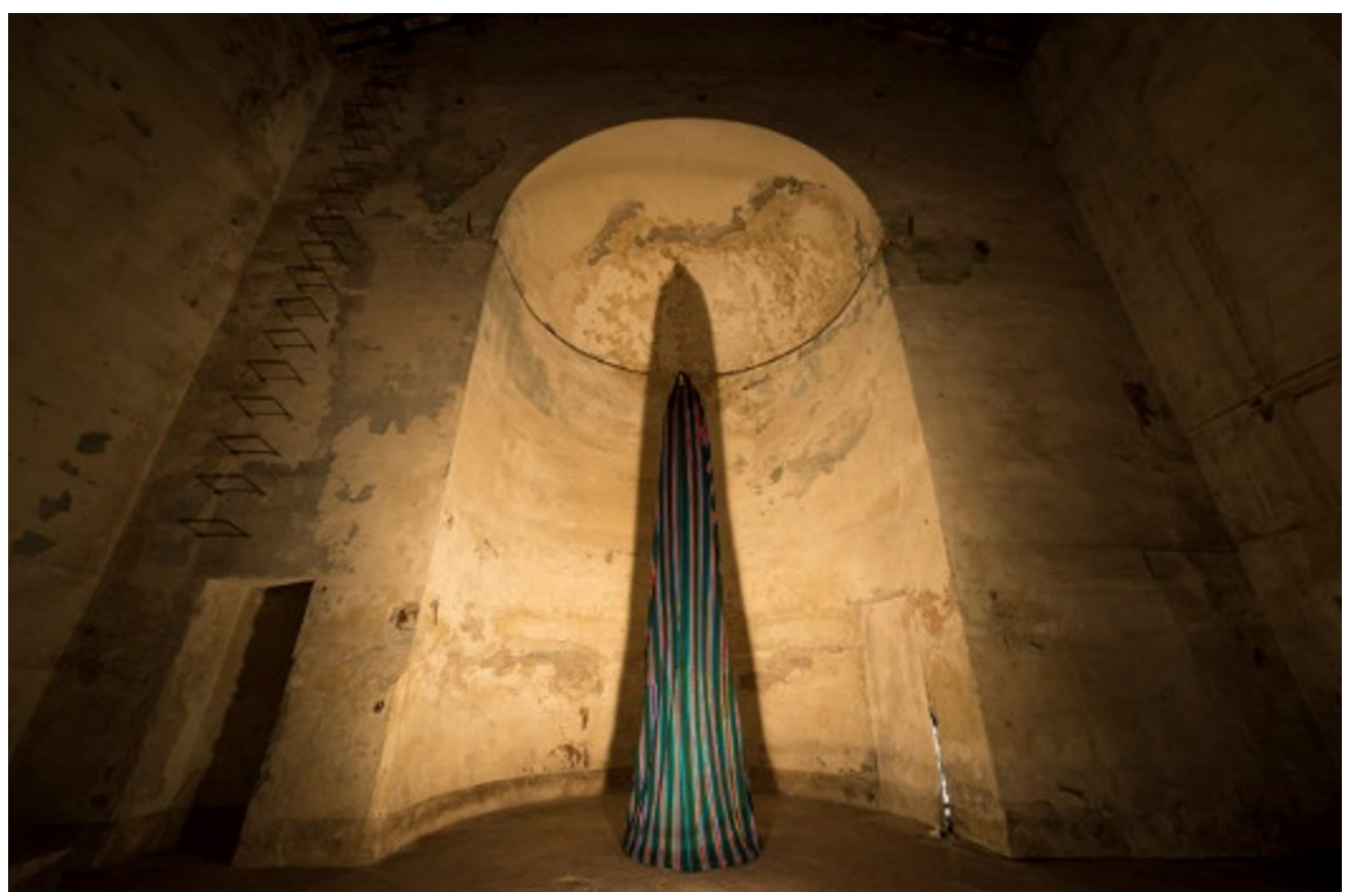

Fuente: Alessi y Lucchesi (2016).

\section{La apropiación de los espacios públicos}

En América Latina, un aspecto en el que las artistas feministas se han enfocado para manifestar la problemática de las mujeres es la apropiación de los espacios públicos, particularmente, la calle. Justamente porque han sido lugares prohibidos que se tornan de gran relevancia como soporte de sus obras, pues allí pueden desplegar y visibilizar su activismo (Antivilo, 2013, p. 127). El primer performance de Galindo, Lo voy a gritar al viento (1999), lo lleva a cabo en un monumento nacional de la Ciudad de Guatemala, el Edificio de Correos y Telégrafos (Antiguo Palacio de Comunicaciones). De allí, se suspende de su elemento más emblemático para leer poemas alusivos a los ultrajes sufridos por mujeres guatemaltecas, los cuales, posteriormente, lanza al vacío. Con esta obra, aprovecha la significación de la institución como ente de transmisión y difusión social para emitir testimonios ocultos en la historia de su país. 
En San Cristóbal de las Casas, ciudad ubicada en el estado de Chiapas, México, y que presenta un entorno político y social similar al guatemalteco, ejecuta Hilo del tiempo (2012). La obra se realizó en una calzada pública, de alto tránsito, donde se acostó introducida dentro de una bolsa tejida para cadáveres con un hilo suelto, el cual debía ser tirado por la audiencia hasta deshacerla para dejar al descubierto su cuerpo desnudo. La descripción de la imagen del performance descifra la metáfora: "hay que ir hacia atrás en el hilo del tiempo para encontrar la razón de tanta muerte y encontrar así la vida" (Galindo, 2012, párr. 1). Este mensaje lo elaboró desde su experiencia de vida y lo divulgó en un espacio de la cotidianidad como una forma de instaurar en el imaginario colectivo las muertes irresolutas por abusos políticos y demandar su indagatoria.

Al ser entrevistada en varios programas de televisión, Galindo ha expresado que su trabajo está orientado a mostrar que la violencia es un comportamiento generalizado (Galindo, 2014a, 21:18), por lo tanto, trasciende las fronteras de su país y de la región. Bajo esta perspectiva se desplaza a otras ciudades, especialmente europeas, para exponer este pensamiento. Quédate (2016) se efectuó en Alemania y consistió en conducir un vehículo marca Mercedes Benz por la ciudad de Hamburgo. En una explanada es detenido por un grupo de jóvenes alemanes quienes, con la artista adentro del auto, lo golpean hasta activar la alarma que suena como una bocina de guerra. El uso de esta bocina alude a la alerta pública de la amenaza migrante. Con ello, denuncia la xenofobia en el pueblo alemán, prejuicio que subyace en la intersubjetividad germana y que es expresado en un sitio donde se instaura y enuncia: la plaza, donde ocurre la interacción social de una comunidad (ver imágenes 8 y 9).

\section{Imagen 8. Quédate}

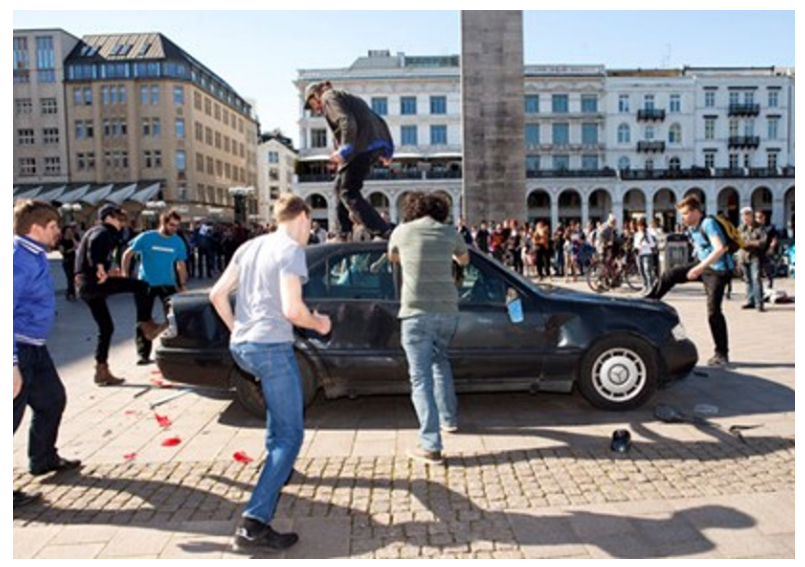

Fuente: Egel (2016).
Imagen 9. Quédate

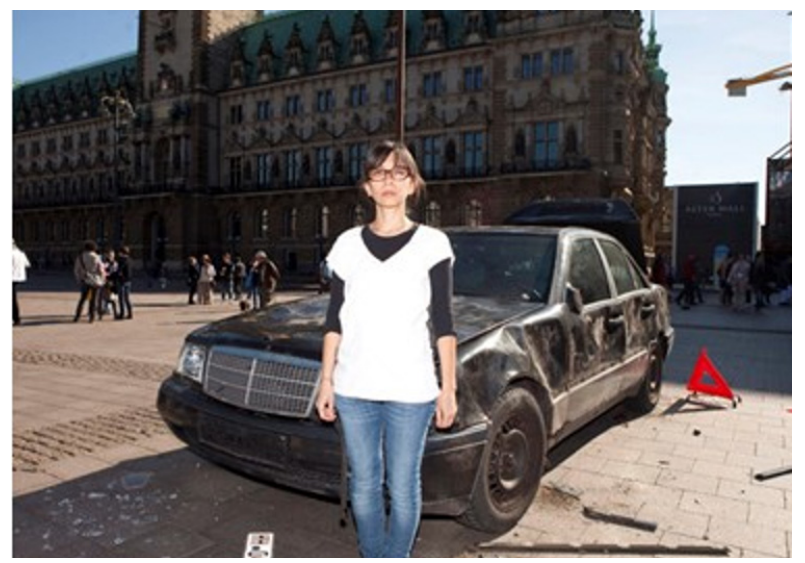

Fuente: Egel (2016). 
Uno de sus últimos trabajos titulado Monumento a los invisibles (2018), que no fue ejecutado en un sitio público, sino en uno de acceso restringido, evidencia el uso deliberado de los espacios para perpetuar discursos y prácticas excluyentes y discriminatorias. El performance se desarrolló en el Patio de Armas del Kings College de la Universidad de Cambridge, zona cuyo césped no puede ser pisado por persona alguna a excepción de becarios o invitados de la Universidad. Ante estas condiciones, Galindo y seis estudiantes del recinto inglés se suspendieron sobre el césped envueltos en una tela neutral. De este modo, emularon monolitos para connotar, además de la segregación, una intimidación que la artista describió como "feeling small [sentirse pequeño]" (citado en Tobin, 2018, párr. 7) y que impugnó al erigirse sobre un espacio prohibido.

Como se ha podido apreciar, los espacios públicos son espacios de enunciación y, por lo tanto, son lugares de disputa, por su aporte en la construcción de memorias e imaginarios con los cuales sedimentar una identidad. En este sentido, Galindo lucha por desmentir aquellos discursos que reproducen la inequidad y ocultan la barbarie. Además, trabaja para visibilizar un pasado que debe ser aceptado, en el caso de Guatemala, mientras que, mundialmente, procura exponer el dolor humano provocado por la discriminación, la expoliación y la ignominia.

\section{El trasfondo del nexo entre arte y sociedad}

Tras analizar las producciones expuestas de Regina José Galindo, se retoma la interrogante que alude a las razones que motivan su creación. En primera instancia, se evidencia una profunda necesidad de denunciar la impunidad como un acto que subsiste de forma subrepticia en la sociedad. Tal arbitrariedad es transversal a los pueblos y queda demostrado en múltiples performances realizados por la artista alrededor del mundo. No obstante, en este quehacer, Galindo ha personificado a cuerpos sociales vilipendiados por las condiciones de vida asociadas a su origen étnico. De esta forma, tanto agrupaciones indígenas ixiles como colectividades migrantes en Europa son integrados en sus propuestas para mostrar a los "pueblos subexpuestos", denominación que establece Didi-Huberman (2014) para referirse a las comunidades que están en peligro de desaparecer por su ocultamiento. Este autor plantea que la subexposición es una privación de la imagen que favorece la impunidad:

La subexposición nos priva sencillamente de los medios de ver aquello de lo que podría tratarse: basta, por ejemplo, con no enviar a un reportero-fotógrafo o un equipo de televisión al lugar de la injustica cualquiera -sea en las calles de París o en 
el otro extremo del mundo- para que esta tenga todas las posibilidades de quedar impune y, así, alcanzar su objetivo (Didi-Huberman, 2014, p. 14).

Se percibe, entonces, que el trabajo de Galindo constituye una imagen de estos pueblos dominados e invisibilizados y trabaja en contrarrestar su negación. Esta intención justifica su incursión recurrente en espacios cotidianos, simbólicos o de alta visitación, así como el empleo de lo abyecto en la estilización de sus obras para perturbar a la audiencia y dimensionar, de alguna manera, la brutalidad de las vejaciones infligidas. Asimismo, su presencia en lugares públicos de enunciación, el registro de sus obras acontecidas en sitios privados, pero que se comparten a través de redes sociales o internet, transforman estos pueblos "borrosos" en pueblos "figurantes" (Didi-Huberman, 2014). Este proceso también se extrapola a otros grupos oprimidos y marginalizados; acto que permite establecer un primer vínculo entre el arte y la sociedad.

A través de esta praxis artística, Galindo deja huella en la sociedad dado que con este gesto realiza una transformación en las discursividades construidas alrededor de los pueblos segregados. Además, trastoca una reminiscencia oficial que es elaborada, legitimada y divulgada por una oligarquía (Galindo, 2014a, 27:32) e involucra, también, figuras, testimonios y eventos censurados o deliberadamente desatendidos. Así, con la incorporación de relatos e imágenes disruptivas en una memoria que se ha instaurado como única y universal, se abre espacio para la exposición de otros actores involucrados en episodios violentos (mártires y agraviados) y contribuye con la divulgación de sus vejámenes, muchos de los cuales no han cesado.

A partir de lo anterior se advierte que, en su desempeño como artista contemporánea, Galindo utiliza el anacronismo al que alude Agamben en sus premisas teóricas. Ella articula distintas temporalidades (pasado y presente) para elaborar una memoria histórica en la que los oprimidos figuran. Esto debido a que busca sus testimonios sobre los ultrajes padecidos en el pasado y los trae al presente para representarlos visualmente en esculturas o en su cuerpo, como lo hizo en las obras anteriormente citadas Testimonios (2014) y Ascensión (2016). De igual forma, otro manejo alegórico del anacronismo como dislocación de un orden temporal se observa en performances que abordan el ciclo de vida. Para ello, la artista refiere a un objeto muerto, sin embargo, se presentan cuerpos que expresan un hálito de vida. En Necromonas (2012), donde el entorno está impregnado de un hedor putrefacto que alude a un organismo en avanzado estado de descomposición, lo que se observa es un ser en buen estado; hay una inconsistencia entre la información que remiten los sentidos 
El arte contemporáneo como reflexión social:

Dossier

una aproximación a la obra de Regina José Galindo

del olfato y de la vista. También, en Desecho (2017) junto a un grupo de bultos con material desechable yace en movimiento Galindo dentro de una bolsa para basura, connotando vida en un conjunto de materia de descarte que se supone inerte y prescindible.

Ante estas tergiversaciones surge una incógnita, ¿cuál es el efecto que producen estas alteraciones? Su respuesta conduce a una segunda vinculación entre el arte y la sociedad: mediante la observación de situaciones inusitadas y su involucramiento en ellas, se genera en el individuo una pérdida del sentido que lo abstrae de su rutina diaria. A través del performance y el happening, Galindo guía a su audiencia a superar la contemplación y la lleva a un cuestionamiento a través de la ruptura de un orden prestablecido. Con ello, promueve el ejercicio reflexivo en el sujeto en quien despierta el asombro y lo hace más receptivo hacia la realidad dentro de la que está inmerso.

La provocación artística se produce cara a cara, o sea, enfrenta al ser humano y lo instiga directamente para sustraerlo de la indolencia. Se interpreta que los temas que trata la artista en sus obras son comunes y cotidianos, pero tienden a pasar desapercibidos por dos razones: la sobreexposición y el enmascaramiento en medios de comunicación masiva que los han vuelto parte de la rutina. Con respecto a la primera razón, conviene citar de nuevo el texto de Didi-Huberman, Pueblos expuestos, pueblos figurantes (2014) para explicar que, de forma similar a lo que ocurre con la subexposición, al sobre exponer una imagen se neutraliza su significado porque "demasiada luz ciega" (p. 25); es decir, su recurrencia ya no sorprende y conduce a la invisibilización. Este mismo efecto se logra también mediante la presentación frecuente de distractores que desvían la atención hacia otros tópicos más gratificantes, propios de la industria del entretenimiento, lo cual alude a la segunda causa de indiferencia señalada.

En vista de estas circunstancias, la artista apela a lo siniestro que implica lo abyecto y aprovecha su estética para hacer reaccionar al público. La exposición de fluidos corporales en su propuesta visual refiere a la esencia animal que sobrelleva el ser humano y aflora en el abuso. Con esta intención se pretende, de forma paralela, mostrar el binomio que convive en la vejación: la víctima y el victimario. Para ello, no solo recurre al uso simbólico de esos fluidos, sino que también emula los ultrajes e incorpora en algunos performances a sujetos que han cometido actos de agresión como, por ejemplo, un expandillero, una pugilista o un torturador.

Como bien lo ha mencionado la artista en entrevistas sobre su trabajo (Galindo, 2014a) sus obras no están planificadas para ofrecer una única lectura. Por el contrario, son concebidas como provocaciones dirigidas a las personas comunes, para que estas se 
pronuncien respecto a eventos o situaciones particulares que deben ser expuestas y tratadas por la impronta que marcan en la sociedad. Entonces, para lograr un contacto con el público, Galindo no solo expone sus performances fuera de espacios consagrados al arte, como los museos, sino que, adicionalmente, los contextualiza. Con esta práctica reafirma la contemporaneidad de su trabajo, pues establece "una relación singular con el propio tiempo" (Agamben, 2011, p. 18) al mantener una mirada crítica de su época. A la vez, introduce un tercer vínculo entre el arte y la sociedad: la presencia del contexto.

Las imágenes de las obras de Galindo son un corpus discursivo, cuya función es mediar entre el texto y el contexto. Es decir, constituyen un grupo de elementos que refieren a una situación social, histórica y cultural con los cuales se trasciende la inmanencia de un texto (Ramírez-Caro, 2016, p. 52). Si bien esta noción es de uso común en el ámbito de la lingüística, se considera pertinente la cita en este apartado por aludir al carácter simbólico de los objetos, condición que está marcada por su devenir y su entorno.

En el caso de las obras de la artista en cuestión se observa que abordan temas de género y poder, principalmente, tópicos que ameritan ser situados por su generalidad, sin dejar de advertir su transversalidad en múltiples dimensiones sociales. No obstante, para lograr instaurar una comunicación entre el texto -en este caso el performance- y la sociedad es necesario recurrir a cogniciones compartidas (Ramírez-Caro, 2016), por lo que se apela a experiencias del dominio público. Dichas cogniciones se gestan, desarrollan y difunden en esferas sociales particulares y de allí son tomadas por la artista para elaborar sus obras. De modo tal que, al igual que en el arte contemporáneo en general, la obra de Galindo demanda del espectador una aprehensión que lo conduce a dos esfuerzos que exponen la vinculación de la obra con su contexto. Uno es rememorar cuando descifra el discurso de la obra y el otro es indagar sobre la realidad bajo la cual se concibe la pieza, en caso de que lo proyectado resulte ilegible.

\section{A modo de cierre}

Sin duda alguna, la indignación ante la impunidad del delito es una de las causas que motiva a Regina José Galindo a crear, por esta razón, sus obras son múltiples expresiones de la transgresión. Lo que surgió como parte de un fuerte de apego socio-territorial a su entorno, dado el arraigo que ha expresado al país que la vio nacer, ha cambiado y se ha tornado visceral al observar que el abuso y la arbitrariedad no conoce fronteras y continúan cobrando víctimas, muchas de ellas femeninas. 
El arte contemporáneo como reflexión social:

Dossier

una aproximación a la obra de Regina José Galindo

Esta consideración invariable, desde que inició su carrera, la nutre e impulsa para seguir, quizás sin quererlo, con un activismo político que la ubica en distintos escenarios según su quehacer: teje memoria, reconstruye relatos y materializa el ultraje en la mujer. En consecuencia, cuestiona la imagen idealizada y reivindica a aquellas quienes han sido denostadas. Se arropa con el sufrimiento de grupos vulnerables y usa su cuerpo para expresar su testimonio. Adicionalmente, se apropia de escenarios públicos de enunciación controlados por quienes, de acuerdo con su criterio, son los responsables de las infamias que han lesionado al pueblo.

A Galindo se le ubica como una representante del arte contemporáneo sin una designación espacial o de origen debido a esta actitud contestataria ante el devenir histórico -que la remite a un territorio específico- por la escogencia de sus temas; a la influencia de sus referentes artísticos en los performances y happenings; a la selección de los espacios donde se ha proyectado su trabajo, y a su incursión en ámbitos creativos globales. En este sentido, cabe agregar que la contemporaneidad en Regina está marcadamente expuesta en la interpelación que realiza al tiempo y al contexto; ejercicio que no implica la constricción a un espacio físico determinado. En esa interacción, impulsada por su praxis artística y social, ella muestra que sus obras no son concepciones azarosas, sino producto de la lectura crítica de un presente. Este ejercicio se constata en aspectos relacionados con el arte y la sociedad, como los identificados y desarrollados anteriormente: la construcción de la imagen de pueblos figurantes, la pérdida de sentido de orden en el espectador y la incidencia del contexto.

De esta forma, la artista ejemplifica la premisa de Nathalie Heinich quien afirma que el arte es una forma de actividad social (2002, p. 43). Con ello, sustrae de la disciplina artística la concepción clásica circunscrita a categorías estéticas determinadas y connota su dependencia de la sociedad. Por consiguiente, este viraje amerita la provisión de múltiples acervos para su comprensión. En este sentido, se considera que la reflexión sobre el arte contemporáneo, al tomar como referencia el trabajo de Regina José Galindo, debe ir acompañada del acopio de insumos y estrategias que faciliten su comprensión. El espacio que circunda al individuo es cada vez más amplio y los discursos que asimila son profusos y heterogéneos. Por lo tanto, es necesario pensar en su preparación para así incorporar en su cosmovisión los mensajes que proceden de estas propuestas visuales disruptivas.

ESCENA. Revista de las artes, 2021, Vol. 80, Núm. 2 (enero-junio), pp. 171-197 


\section{Referencias}

Agamben, G. (2011). Desnudez. Buenos Aires: Adriana Hidalgo Editora.

Aguirre-Tobón, K. (2014). Analizando la violencia después del conflicto: el caso de Guatemala en un estudio sub-nacional. Revista Mexicana de Ciencias Políticas y Sociales, (220), 191-234. Recuperado de http://www.scielo.org.mx/pdf/rmcps/ v59n220/v59n220a7.pdf

Alessi, V. \& Lucchesi, D. (2016). Ascensión [Fotografía]. Recuperado de http://www. reginajosegalindo.com/ascencion/

Antivilo-Peña, J. (2013). Arte feminista latinoamericano. Rupturas de un arte político en la producción visual (tesis doctoral). Universidad de Chile, Chile. Recuperado de http://repositorio.uchile.cl/handle/2250/114336

Chiquin, C. (25 junio de 2013). La dignidad amaneció en los ojos del pueblo Ixil. Comunicarte. Recuperado de http://noticiascomunicarte.blogspot.com/2013/06/la-dignidad-amanecio-en-los-ojos-del.html

Ciénega-Valerio, E. P. (s.f.). Mutaciones del cuerpo: hacia la construcción de nuevas formas de subjetivación y sus implicaciones éticas. Reflexiones en torno a lo abyecto en las prácticas contemporáneas. Recuperado de http://www.iztacala.unam.mx/ errancia/v1/PDFS_1/POLIETICAS1_MUTACIONESDEL CUERPO.pdf

De León, Q. (13 de setiembre de 2017). ¿Por qué el gobernador de Quetzaltenango censuró una obra de arte? Medium. Recuperado de https://medium.com/@ PrensaComunitar/por-qu\%C3\%A9-el-gobernador-de-quetzaltenango-censur\%C3\%B3-una-obra-de-arte-2e07d62af753

Didi-Huberman, G. (2006). Ante el tiempo. Historia del arte y anacronismo de las imágenes. Buenos Aires: Adriana Hidalgo Editora.

Didi-Huberman, G. (2014). Pueblos expuestos, pueblos figurantes. Buenos Aires: Ediciones Manantial.

DW en español. (20 de febrero 2014a). Regina José Galindo, artista guatemalteca. Alemania con acento (entrevista por Pía Castro) [Video de YouTube]. Recuperado de https://www. youtube.com/watch?v=gVsKhr2BNSk\&ab_channel=DWEspa\%C3\%B1ol 
El arte contemporáneo como reflexión social:

Dossier

una aproximación a la obra de Regina José Galindo

Egel, F. (2016). Quédate [Fotografía]. Recuperado de http://www.reginajosegalindo. com/quedate/

Fondo de las Naciones Unidas para la Infancia [UNICEF] y Comisión Internacional contra la impunidad en Guatemala [CIClG]. (2016). Informe: Trata de personas con fines de explotación sexual en Guatemala. Recuperado de https://www.unicef.org/guatemala/media/311/file/informe\%20de\%20trata\%20de\%20personas.pdf

Galindo, R. J. (s.f.a). Soy un lugar común [página web]. Recuperado de https://www. poemas-del-alma.com/regina-jose-galindo.htm

Galindo, R. J. (s.f.a). Regina José Galindo [sitio web]. Recuperado de http://www.reginajosegalindo.com/

Galindo, R.J. (2007). Mientras ellos siguen libres [página web]. Recuperado de http:// www.reginajosegalindo.com/mientras-ellos-siguen-libres/

Galindo, R.J. (2010). Hermana [página web]. Recuperado de http://www.reginajosegalindo.com/hermana/

Galindo, R.J. (2012). Hilo del tiempo [página web]. Recuperado de http://www.reginajosegalindo.com/hilo-de-tiempo/

Galindo, R.J. (2013). La verdad [página web]. Recuperado de http://www.reginajosegalindo.com/la-verdad/

Galindo, R.J. (2014b). Testimonios [página web]. Recuperado de http://www.reginajosegalindo.com/testimonios/

Galindo, R.J. (2015). Isle'l in [página web]. Recuperado de http://www.reginajosegalindo.com/islel-in/

Galindo, R.J. (2017). Presencia [página web]. Recuperado de http://www.reginajosegalindo.com/presencia/

Heinich, N. (2002). La Sociología del arte. Buenos Aires: Ediciones Nueva Visión.

Heinich, N. (2017). El paradigma del arte contemporáneo: Estructuras de una revolución artística. Madrid: Casimiro Libros. 
Kristeva, J. (1988). Poderes de la perversión. México: Siglo XXI editores. S.A.

La casa encendida. (18 de abril 2017). Regina José Galindo (entrevista) [video]. Recuperado de https://vimeo.com/213652111

Le Breton, D. (2002). La sociología del cuerpo. Buenos Aires: Edición Nueva Visión.

Nari, M. (2016). La siesta [fotografía]. Recuperado de http://www.reginajosegalindo. com/la-siesta/

Pérez, D. (2007). Ablución [fotografía]. Recuperado de http://www.reginajosegalindo. com/ablucion/

Pérez, D. \& Linares, J. (2013). La Verdad [fotografía]. Recuperado de http://www.reginajosegalindo.com/la-verdad/

Ramírez-Caro, J. (2016). Cómo analizar de todo. Textos populares, mediáticos, artísticos y didácticos. Heredia: EUNA.

Tobin, A. (2018). Regina José Galindo in Cambridge. Recuperado de http://www.kettlesyard.co.uk/about/news/regina-jose-galindo-cambridge/ 